\title{
Evolução recente e alguns determinantes da proteção social dos idosos na América Latina e no Brasil
}

\author{
Rogério Nagamine Costanzi e \\ Graziela Ansiliero
}

\section{Introdução}

A existência de um sistema que ofereça seguridade social ou proteção social aos idosos, com ampla cobertura, é de fundamental importância para prevenir o incremento da pobreza. $\mathrm{Na}$ ausência do referido sistema, e frente às transformações demográficas (envelhecimento populacional) e da estrutura familiar (aumento expressivo de famílias cada vez menores), haverá riscos crescentes de que tanto o Brasil quanto a América Latina sofram com problemas de insuficiência de renda entre as pessoas com idade mais avançada.

A América Latina atualmente possui profundas deficiências em termos de proteção social dos idosos e, dadas as tendências demográficas e de estrutura familiar, esse quadro pode-se agravar ainda mais. O cenário torna-se ainda mais preocupante tendo em vista que a globalização financeira, caracterizada por capitais especulativos em busca de ganhos rápidos e elevados, associada a uma inadequada regulamentação, acabou gerando uma crise financeira 
internacional que criou riscos à seguridade social em países da América Latina, os quais realizaram reformas liberais que transformaram regimes de repartição pública em regimes de capitalização de contas individuais, ou combinaram ambos os regimes, como Chile, Colômbia e Argentina - embora este último tenha recentemente voltado à repartição pública.

Dado esse contexto, o presente artigo busca avaliar a situação atual e as perspectivas da proteção dos idosos na América Latina, com foco no caso brasileiro. O texto encontra-se organizado da seguinte forma: a) inicialmente, há um breve relato da evolução recente $\mathrm{da}$ população idosa no Brasil e na América Latina; b) em seguida, apresenta-se um retrato da proteção social de idosos, de forma mais detalhada no Brasil, buscando avaliar seus determinantes; c) na terceira parte, são analisados os efeitos ou impactos sociais da proteção, com foco na participação dos idosos no mercado de trabalho e no nível de pobreza, especialmente no caso brasileiro; d) as considerações finais apontam as perspectivas da proteção social dos idosos no Brasil e na América Latina.

\section{Evolução da população idosa no Brasil e na América Latina}

De acordo com o Estatuto do Idoso, em vigor no Brasil desde janeiro de 2004, são consideradas idosas todas as pessoas com idade igual ou superior a 60 anos. Existem no país cerca de 19,95 milhões de pessoas nessa faixa etária, de acordo com a Pesquisa Nacional por Amostra de Domicílios (PNAD) de 2007. Do total de idosos brasileiros, aproximadamente $44,3 \%$ (8,83 milhões) são homens e 55,7\% (11,1 milhões) são mulheres (Tabela 1).

Os idosos compõem um grupo que, em 2007, representava $10,5 \%$ da população residente no país - percentual que apresenta tendência de crescimento. Três fatores combinados têm contribuído para isso: a) os progressos na medicina e a melhoria nas condições de vida da população favoreceram a elevação da esperança de vida ao nascer, que passou de 42,7 anos em 1940 para 72,6 anos em 2007 (IBGE, 2008a). Há expectativa de que tal indicador chegue a 81,3 anos em 2050; b) redução da taxa de fecundidade, que caiu de seis filhos por mulher, na década de 1960, para 1,95 em 2007, havendo a previsão de queda para 1,5 em 2050; c) embora a taxa de mortalidade tenha sido reduzida significativamente nas últimas décadas, passando de 100 óbitos por mil nascimentos em 1970, para 24,32 por mil em 2007, esse patamar não pode ser considerado baixo para os padrões internacionais (IBGE, 2008b).

A combinação de queda na taxa de fecundidade com redução ainda insuficiente na taxa de mortalidade infantil, somada à elevação da expectativa de vida

Tabela 1: População idosa e população total - Brasil - 2007

\begin{tabular}{l|r|r|r}
\hline \multicolumn{1}{c|}{ Grupo } & \multicolumn{1}{c|}{ Homens } & \multicolumn{1}{c|}{ Mulheres } & \multicolumn{1}{c}{ Total } \\
\hline População idosa (60 anos ou mais) & 8.838 .779 & 11.115 .732 & 19.954 .511 \\
\hline População residente total & 92.625 .387 & 97.194 .943 & 189.820 .330 \\
\hline Participação dos idosos no total (em \%) & $9,54 \%$ & $11,44 \%$ & $10,51 \%$ \\
\hline
\end{tabular}

Fonte: PNAD/IBGE 2007 
ao nascer, tem provocado um processo de envelhecimento da população brasileira, com a diminuição relativa da população jovem e, consequentemente, o aumento da participação dos idosos no total. Essa situação fica visível no Gráfico 1, que apresenta a evolução da participação relativa dos idosos na população brasileira. Segundo os dados da PNAD, entre 1992 e 2007, a taxa de participação dos idosos na população aumentou sensivelmente, tendo passado de $7,9 \%$ para $10,6 \%$.

Segundo os dados da projeção da população de 1980-2050, considerando a revisão de 2008, a participação dos idosos (60 anos ou mais), que cresceu de 6,1\% em 1980 para $9,5 \%$ em 2008, passaria para $13,7 \%$ e $29,8 \%$, em 2020 e 2050 , respectivamente. $\mathrm{O}$ número de pessoas de 60 anos ou mais aumentaria de 18 milhões, em 2008, para 64 milhões em 2050.
Também projeta-se aumento da importância relativa das pessoas com 80 anos ou mais, que têm maior probabilidade de sofrer com problemas de dependência funcional (BATISTA; JACCOUd; Aquino \& Dario El-Moor, 2008). De acordo com os dados da projeção, os brasileiros nessa faixa etária devem passar de $1,27 \%$ da população, em 2008, para $1,93 \%$ e $6,39 \%$, respectivamente, em 2020 e 2050. Em termos absolutos, segundo os dados de projeção da população, os com 80 anos ou mais passariam dos atuais 2,4 milhões (2008) para 13,7 milhões em 2050.

Essa alteração da estrutura etária da população, com aumento da participação relativa dos idosos, obviamente implica a necessidade de mudanças nas políticas públicas e no planejamento, bem como torna, a longo prazo, o desafio da proteção social dos idosos ainda mais importante

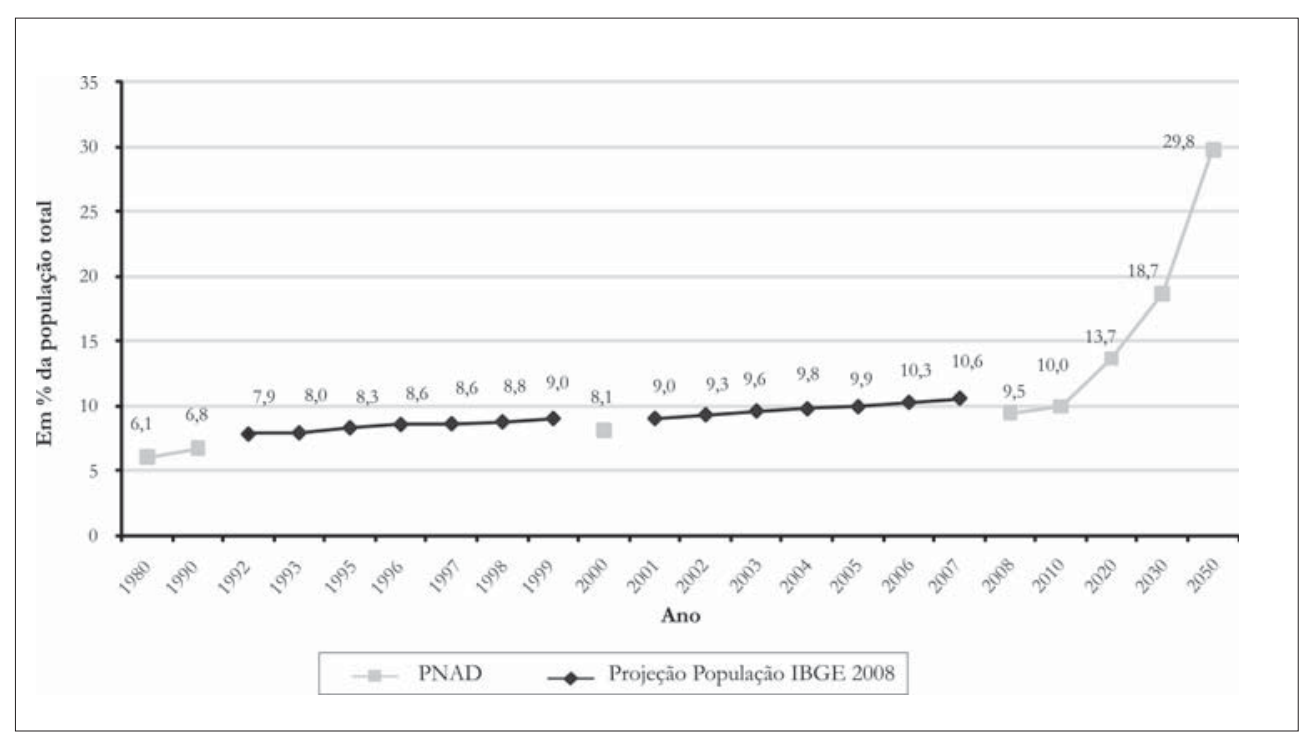

Fonte: PNAD/IBGE 1992 e 2007 (exclusive área rural do Norte, exceto Tocantins) e Projeção da População 19802050 - Revisão/2008.

Gráfico 1: Participação dos idosos na população do país (em\% do total) - Brasil, 1980 a $2050^{1}$ 
para a sociedade - um desafio mais difícil e custoso. Implica, também, a realocação ou reestruturação do gasto público ao longo do tempo.

Vale mencionar que não apenas a expectativa de vida entre homens e mulheres é distinta, mas o incremento da esperança de vida tem sido ligeiramente mais pronunciado entre as mulheres. Como resultado, a expectativa de vida é superior para as mulheres em todas as faixas etárias, ainda que os diferenciais por sexo diminuam com a idade. Esses fenômenos têm levado a uma "feminilização" do envelhecimento populacional. Os homens, em especial quando jovens, também são vítimas mais comuns da violência.

O envelhecimento populacional observado no Brasil é, na realidade, um processo mundial, que também está ocorrendo na América Latina, no Caribe e na grande maioria dos países da referida região (Batista; Jaccoud; Aquino \& Dario
EL-Moor, 2008). Segundo o referido estudo, depois de aumentar de 5,9\% em 1950 para 8\% em 2000, a participação das pessoas com 60 anos ou mais na população total representará 22,5\% em 2050, na América Latina e Caribe.

As projeções e dados do Centro Latino-Americano e Caribenho de Demografia da Comissão Econômica para a América Latina e o Caribe (Celade/Cepal) apontam que a participação das pessoas de 60 anos ou mais na população total, depois de subir de 5,5\% em 1950 para 8,1\% em 2000, cresceria para 23,6\% em 2050 (Gráfico 2). Em termos absolutos, a população de 60 anos ou mais na referida região, que era de 41,6 milhões em 2000, alcançaria o patamar de 180,3 milhões em 2050. Já o percentual de pessoas com 80 anos ou mais, que cresceu de $0,4 \%$ para $1 \%$ no período de 1950 a 2000, atingiria o patamar de 4,6\% em 2050. Em termos absolutos, a população com 80 anos ou mais, que passou de

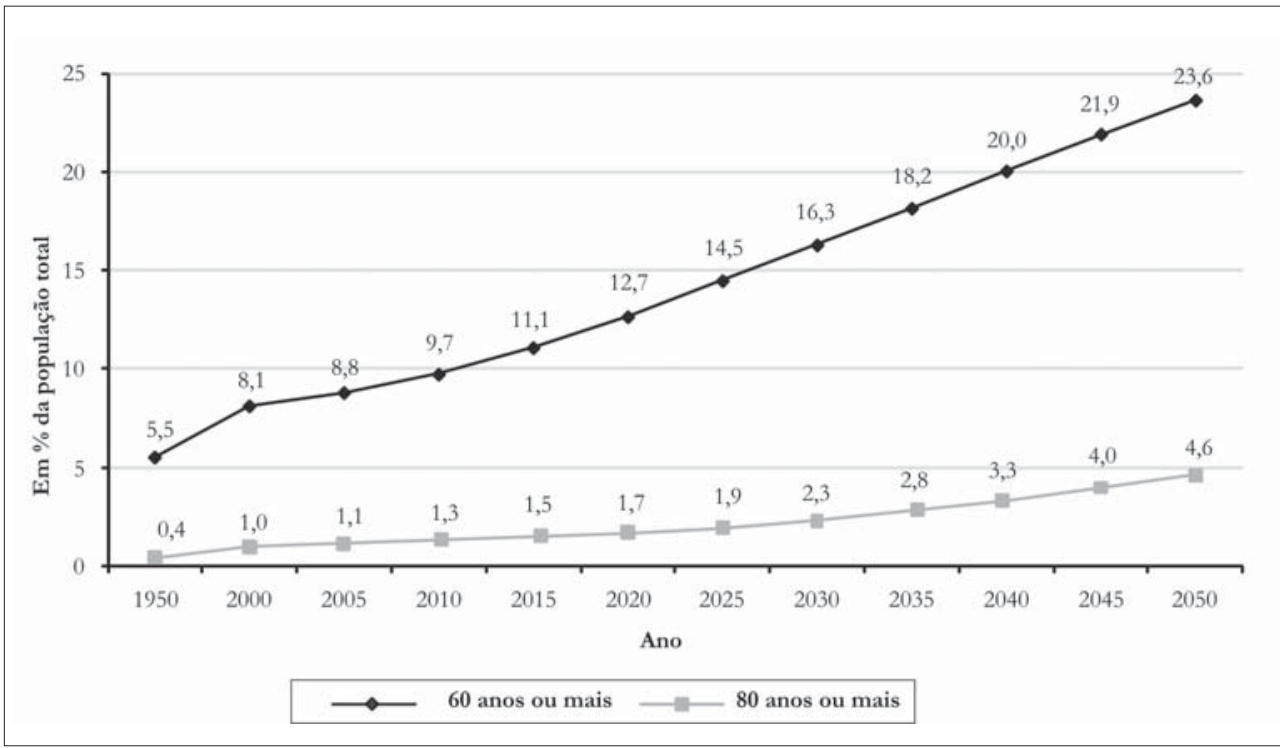

Fonte: Elaboração própria a partir de dados da Celade/Cepal.

Gráfico 2: Participação dos idosos na população total (em \%) - América Latina e Caribe, 1950 a 2050 
679 mil em 1950 para 4,9 milhões em 2000, chegaria a 35,1 milhões em 2050.

Em 2010, segundo projeções do Celade, haverá na América Latina cerca de 56,8 milhões de idosos com 60 anos ou mais, correspondendo a 9,7\% da população total (582,6 milhões). Desses, 25,7 milhões serão homens (45,3\%) e 31 milhões $(54,7 \%)$ serão mulheres. Enquanto a participação de idosos entre a população masculina será de $8,9 \%$, entre as mulheres esse percentual será de 10,5\%.

O comportamento demográfico descrito - que combina aumento do contingente de idosos, bem como o incremento de sua participação na população total, e a redução da taxa de fecundidade - provoca efeitos importantes na Previdência Social. Por um lado, esses fatores tendem a gerar elevação da despesa previdenciária em função do crescimento absoluto da população idosa e, por outro, tendem a resultar em redução das taxas de crescimento da população potencialmente ativa e, consequentemente, da principal fonte de arrecadação da Previdência Social - a contribuição dos trabalhadores ativos (pelo menos em regimes de repartição). Em outras palavras, caminha-se para um agravamento da razão de dependência da população idosa tanto no Brasil quanto na América Latina (Tabela 2).

No Brasil, enquanto em 2008 havia 10,26 pessoas de 15 a 64 anos para cada indivíduo com 65 anos ou mais, em 2050 haverá apenas 2,82 indivíduos na idade economicamente ativa para cada idoso. $\mathrm{Na}$ América Latina, de forma similar, em 2005 havia 10,49 pessoas de 15 a 64 anos para cada idoso de 65 anos ou mais. Essa relação, em 2050, deve cair para 3,58.

Contudo, o aumento das responsabilidades, em termos de dependência, que as pessoas de 15 a 64 anos irão sofrer, em função do aumento de idosos, será compensado, em parte, até 2020, com a diminuição da população de 0 a 14 anos, tanto no Brasil quanto na América Latina (Tabela 2). No período de 2020 a 2050, essa relação também irá se deteriorar.

Há uma profunda mudança de composição dos dependentes, que passam a ser cada vez mais idosos, em lugar de crianças e adolescentes. Em 2008, por exemplo, no Brasil, cada pessoa de 15 a 64 anos teria que cuidar de 0,49 dependentes, sendo 0,1 idoso e 0,39 criança/adolescente. Naquele ano, de um total de 62,6 milhões de dependentes, 50,2 milhões (80,2\% do total) tinham de 0 a 14 anos e 12,4 milhões eram pessoas com 65 anos ou mais (19,8\% do total). As projeções indicam que, em 2050, cada pessoa de 15 a 64 anos teria de cuidar de 0,56 dependentes, sendo 0,35 idosos e 0,21 crianças/adolescentes. De um total de 77,2 milhões de dependentes, cerca de 48,9 milhões seriam idosos de 65 anos ou mais $(63,3 \%)$ e 28,3 milhões, crianças e adolescentes de 0 a 14 anos (36,7\%).

$\mathrm{Na}$ América Latina também se observa alteração semelhante, tendo em vista que, do total de 197 milhões de dependentes em $2005,16,9 \%$ eram idosos e $83,1 \%$, crianças/ adolescentes; em 2050, de um total de 274,3 milhões de dependentes, 49,7\% serão pessoas de 65 anos ou mais e 50,3\%, indivíduos de 0 a 14 anos.

Certamente essa profunda alteração da estrutura etária dos dependentes precisa ser levada em consideração na definição das áreas prioritárias para os gastos públicos, para o planejamento e para o desenho das políticas de proteção social. Mais que isso, nesse contexto de envelhecimento populacional e piora da relação de dependência, é fundamental que as políticas de seguridade social sejam reforçadas sob pena de comprometer a proteção social de parcela crescente da população. 
Tabela 2: Relação de dependência Brasil e América Latina 1980-2050

\begin{tabular}{|c|c|c|c|c|c|c|c|}
\hline \multicolumn{8}{|c|}{ Brasil } \\
\hline Ano & $\begin{array}{l}\text { População } \\
15 \text { a } 64 \text { anos } \\
\text { (a) }\end{array}$ & $\begin{array}{l}\text { População } \\
65 \text { anos ou } \\
\text { mais } \\
\text { (b) }\end{array}$ & $\begin{array}{c}\text { População } \\
0 \text { a } 14 \text { anos } \\
\text { (c) }\end{array}$ & $b+c$ & (a) / (b) & (a) $/$ (c) & (a) $/(b+c)$ \\
\hline 1980 & 68.464 .223 & 4.758 .476 & 45.339 .850 & 50.098 .326 & 14,39 & 1,51 & 1,37 \\
\hline 2000 & 110.951 .338 & 9.325 .607 & 51.002 .937 & 60.328 .544 & 11,90 & 2,18 & 1,84 \\
\hline 2008 & 127.048 .354 & 12.377 .850 & 50.186 .610 & 62.564 .460 & 10,26 & 2,53 & 2,03 \\
\hline 2020 & 146.447 .173 & 19.124 .736 & 41.571 .334 & 60.696 .070 & 7,66 & 3,52 & 2,41 \\
\hline 2050 & 138.081 .864 & 48.898 .647 & 28.306 .952 & 77.205 .599 & 2,82 & 4,88 & 1,79 \\
\hline \multicolumn{8}{|c|}{ América Latina } \\
\hline Ano & $\begin{array}{c}\text { População } \\
15 \text { a } 64 \text { anos } \\
\text { (a) }\end{array}$ & $\begin{array}{c}\text { População } \\
65 \text { anos ou } \\
\text { mais } \\
\text { (b) }\end{array}$ & $\begin{array}{c}\text { População } \\
0 \text { a } 14 \text { anos } \\
\text { (c) }\end{array}$ & $b+c$ & (a) / (b) & (a) $/$ (c) & (a) $/(b+c)$ \\
\hline 1980 & 198.544 .360 & 15.601 .418 & 140.554 .303 & 156.155 .721 & 12,73 & 1,41 & 1,27 \\
\hline 2000 & 319.772 .564 & 28.683 .464 & 163.278.614 & 191.962.078 & 11,15 & 1,96 & 1,67 \\
\hline 2005 & 349.651 .078 & 33.346 .368 & 163.666.236 & 197.012 .604 & 10,49 & 2,14 & 1,77 \\
\hline 2020 & 431.772 .405 & 56.217 .272 & 160.090 .341 & 216.307 .613 & 7,68 & 2,70 & 2,00 \\
\hline 2050 & 488.359 .687 & 136.425 .589 & 137.893 .055 & 274.318 .644 & 3,58 & 3,54 & 1,78 \\
\hline
\end{tabular}

Fonte: Elaboração dos autores a partir de dados do IBGE e do Celade.

Evolução da proteção social de idosos no Brasil e na América Latina

No Brasil, apesar da expansão expressiva da população idosa descrita brevemente no tópico anterior, a Previdência Social tem logrado aumentar a taxa de cobertura social das pessoas com 60 anos ou mais, muito embora persista um desequilíbrio na proteção de homens e mulheres nessa faixa etária. Grosso modo, é considerado idoso com proteção social aquele que, segundo os dados da PNAD, recebe benefício de pensão ou aposentadoria, ou continua trabalhando com contribuição para a previdência, conforme metodologia empregada pelo Ministério da Previdência Social e aprovada pelo Conselho Nacional de Previdência Social - CNPS (Schwarzer; Paiva \& Santana, 2004 e Costanzi \& Ansiliero, 2008).
Na série harmonizada da PNAD, que desconsidera a área rural da Região Norte (salvo Tocantins), a parcela da população idosa protegida socialmente - que recebe aposentadoria e/ou pensão de qualquer regime previdenciário ou da assistência social e/ou contribui para a Previdência Social - passou de aproximadamente $74 \%$ em 1992 para 80,7\% em 2007.

$\mathrm{O}$ recorte de gênero evidencia que tais melhoras, especialmente as ocorridas entre 1992 e 2002 (Gráfico 3), resultam em grande medida do aumento da proteção de idosos do sexo feminino ( $+11,77$ pontos percentuais entre 1992-2002), uma vez que a série referente aos homens idosos permaneceu relativamente estável nesse mesmo período $(+2,41$ pontos percentuais). O aumento da cobertura entre as idosas pode ser resultado do incremento da participação das mulheres na população 


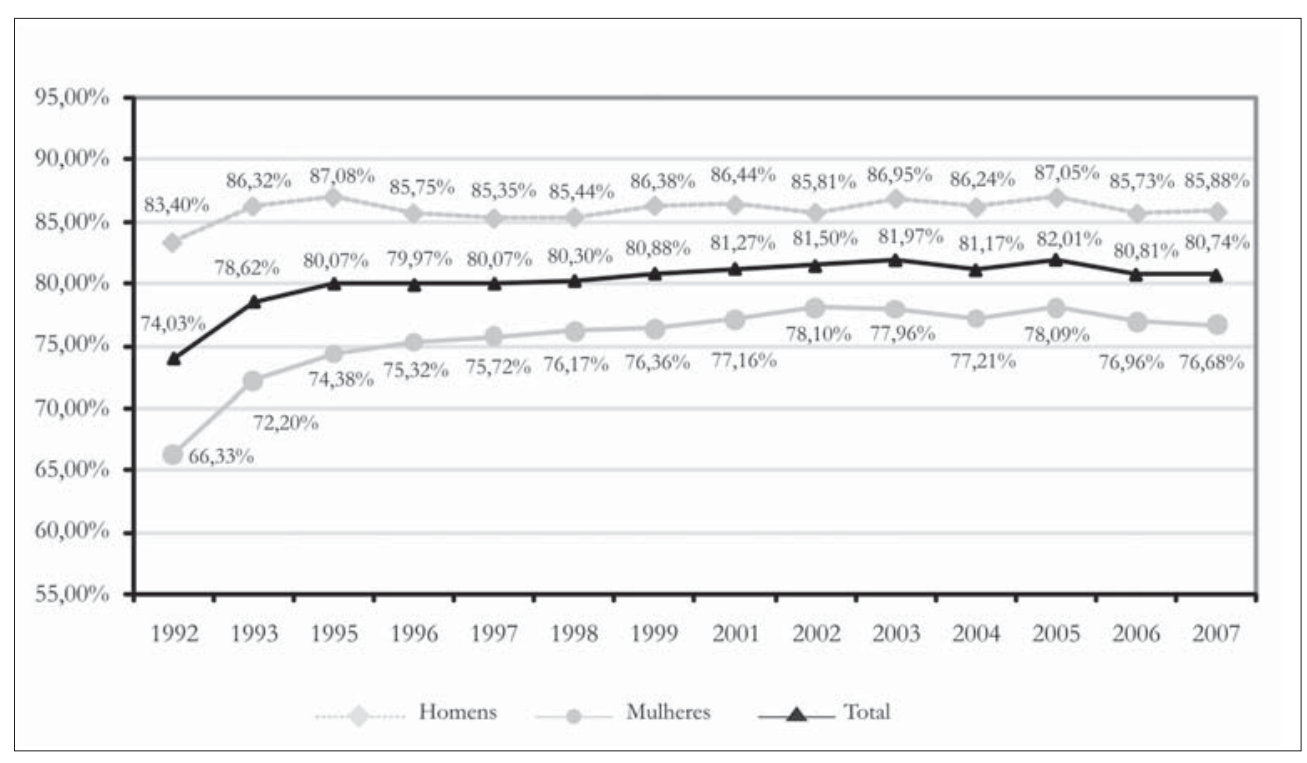

Fonte: Elaboração própria a partir dos microdados da PNAD/IBGE - 1992 a 2007.

\section{Gráfico 3: Brasil - Idosos de 60 anos ou mais que recebem aposentadoria e/ou pensão ou que continuam contribuindo para algum regime previdenciário ( $\mathrm{em} \%$ ), 1992 a 2007}

ocupada, fenômeno intensificado nas últimas décadas. A longo prazo, a confirmação dessa tendência pode reduzir as disparidades na proteção de homens e mulheres idosos.

Entre os idosos, o aumento na proteção também pode estar relacionado à ampliação do número de beneficiários da Lei Orgânica da Assistência Social (Loas). As recentes alterações promovidas pelo Estatuto do Idoso expandiram ainda mais o público beneficiário dos chamados benefícios de prestação continuada (BPC), afetando positivamente a cobertura dos idosos com 65 anos ou mais. ${ }^{2}$ Além disso, a evolução positiva observada de 1992 a 2005 está indubitavelmente associada à instituição da categoria de segurado especial, regulamentada em 1991, a qual possibilitou o crescimento significativo da cobertura previdenciária no meio rural, notadamente entre as mulheres. ${ }^{3}$
Nos dois últimos anos, a PNAD aponta para ligeira redução na taxa de proteção dos idosos, queda essa mais acentuada entre as mulheres. Entre 2005 e 2007 , muito embora o contingente de protegidos tenha aumentado sensivelmente (2007/ 2006: 3,8\%; 2006/2005: 2,9\%), a taxa de crescimento foi inferior à observada na população idosa total (2007/2006: 4,5\%; 2006/2005: 4,5\%). Nesses dois anos, parece ter havido uma inversão no ritmo de expansão dos dois grupos, resultado que pode ser explicado, em parte, pelo aumento na expectativa de vida da população em geral. Esse fenômeno tem possibilitado a inclusão na população idosa de camadas mais vulneráveis da sociedade, para as quais a contribuição previdenciária tende a ser mais limitada durante a vida ativa. ${ }^{4}$

Ocorre que os indicadores de cobertura apresentados encontram-se subestimados em 2004, 2006 e 2007, anos em 
que a PNAD registrou os benefícios de prestação continuada na categoria "outros rendimentos". Nos demais anos, é provável que uma grande parcela desses benefícios tenha sido contabilizada como aposentadoria ou pensão. ${ }^{5}$ De todo modo, a cobertura previdenciária da população idosa brasileira é bastante expressiva, mesmo quando comparada ao nível de proteção alcançado nos países desenvolvidos, destacando-se entre as nações em desenvolvimento.

Tomando-se apenas 2007, quando a taxa de cobertura nacional (incluindo a área rural da Região Norte) chegou a 80,6\%, os idosos socialmente protegidos totalizavam 16,1 milhões de pessoas, sendo 7,6 milhões de homens e 8,5 milhões de mulheres. A proteção social entre os homens chegou a 85,6\%, resultado consideravelmente superior ao observado entre as mulheres $(76,6 \%)$. Os dados apontam para a existência de concentração relativa e absoluta de idosas socialmente desprotegidas. Aproximadamente 67,1\% dos desprotegidos são do sexo feminino e as mulheres representam 55,7\% do total de pessoas com idade igual ou superior a 60 anos. Em outras palavras, as mulheres idosas possuem a maior participação absoluta e estão sobrerrepresentadas entre o total de idosos socialmente desprote- gidos. Em 2007, a proporção de idosas desprotegidas correspondia a 1,2 vez a participação de mulheres na população idosa total (Tabela 3).

Esses números podem estar associados ao fato de que a participação das mulheres no mercado de trabalho - embora venha apresentando evolução positiva contínua nas últimas décadas - ainda tende a ser sistematicamente inferior à dos homens, sendo que a geração das idosas que atualmente possuem 60 anos ou mais possivelmente experimentou taxas de participação ainda mais baixas. Além disso, a ocupação em condições precárias e a taxa de desemprego tendem a ser mais elevadas entre as mulheres. Consequentemente, em face da elevada correlação existente entre ocupação e contribuição previdenciária, é provável que esse indicador esteja apenas refletindo a dinâmica do mercado de trabalho vivenciada pelas mulheres, atualmente idosas, durante a idade ativa.

Em 2007, as mulheres eram maioria absoluta entre os pensionistas - 93,2\% do total de pessoas que recebem apenas pensão - , enquanto os homens são maioria, embora com diferencial menos expressivo, entre aqueles que recebem aposentadoria - 58,5\% do total de pessoas que recebem apenas esse benefício. Entre os que acumulam os dois benefícios, mais

Tabela 3: Proporção de idosos* residentes no país (A) e idosos desprotegidos (B), 2007

\begin{tabular}{l|c|c|c|c}
\hline \multicolumn{1}{c|}{ Sexo } & $\begin{array}{c}\% \text { Total de idosos } \\
\text { (a) }\end{array}$ & $\begin{array}{c}\% \text { idosos } \\
\text { desprotegidos (b) }\end{array}$ & (b)/(a) & $\begin{array}{c}\text { Total de } \\
\text { desprotegidos }\end{array}$ \\
\hline Homens & $44,3 \%$ & $32,9 \%$ & 0,7 & 1.272 .740 \\
\hline Mulheres & $55,7 \%$ & $67,1 \%$ & 1,2 & 2.601 .053 \\
\hline Total & $100 \%$ & $100 \%$ & - & 3.873 .793 \\
\hline
\end{tabular}

Fonte: PNAD/IBGE - 2007. Elaboração: SPS/MPS.

* Pessoas com 60 anos ou mais de idade. 
Tabela 4: Cobertura social entre os idosos com 60 anos ou mais de idade, segundo sexo e tipo de benefício - 2007

\begin{tabular}{l|r|r|r|r|r}
\hline \multicolumn{1}{c|}{ Categorias } & Homens (a) & \% (a / c) & Mulheres (b) & \% (b / c) & \multicolumn{1}{c}{ Total (c) } \\
\hline Aposentados & 6.558 .689 & $58,5 \%$ & 4.657 .134 & $41,5 \%$ & 11.215 .823 \\
Pensionistas & 176.409 & $6,8 \%$ & 2.417 .931 & $93,2 \%$ & 2.594 .340 \\
Aposentados c pensionistas & 190.761 & $13,8 \%$ & 1.187 .887 & $86,2 \%$ & 1.378 .648 \\
Contribuintes não beneficiários & 640.180 & $71,8 \%$ & 251.727 & $28,2 \%$ & 891.907 \\
\hline Total protegidos (a) & $\mathbf{7 . 5 6 6 . 0 3 9}$ & $47,1 \%$ & $\mathbf{8 . 5 1 4 . 6 7 9}$ & $\mathbf{5 2 , 9} \%$ & $\mathbf{1 6 . 0 8 0 . 7 1 8}$ \\
\hline Residentes (b) & 8.838 .779 & - & 11.115 .732 & - & 19.954 .511 \\
\hline Total de proteção (a) (b) (em \%) & $\mathbf{8 5 , 6 \%}$ & - & $\mathbf{7 6 , 6} \%$ & - & $\mathbf{8 0 , 6 \%}$ \\
\hline
\end{tabular}

Fonte: PNAD/IBGE - 2007. Elaboração: SPS/MPS.

uma vez a participação das mulheres é significativamente superior $(86,2 \%)$, conforme mostra a Tabela 4.

A elevada proporção de mulheres entre os pensionistas deve estar ligada à maior expectativa de vida desse grupo populacional. Como em média vivem mais, é natural que enviúvem mais frequentemente que os homens, tornando-se beneficiárias de pensão e, muitas vezes, chefes da unidade familiar. A menor participação das mulheres entre os aposentados, por sua vez, pode estar atrelada a questões culturais e econômicas. A população feminina atualmente em idade de aposentadoria provavelmente participou do mercado de trabalho com menos frequência que os homens e em condições bastante distintas, conforme mencionado anteriormente.

De um modo geral, na América Latina prevalece um baixo grau de proteção social entre os idosos, sendo que o Brasil possui um dos níveis mais elevados da região (Quadro 1). Como mostrado por Rofman \& Luccheti (2007), a cobertura dos idosos - entendida como o percentual que recebe algum tipo de benefício contributivo ou não contributivo - indica que a proteção social dessa população na América Latina é extremamente baixa em muitos países da referida região. Essa cobertura seria igual ou superior a $60 \%$ da população idosa apenas na Costa Rica (60,09\%, sendo $39,42 \%$ contributivo e $20,12 \%$ não contributivo, em 2004), Argentina (68,8\% em 2006), Bolívia (14,7\% contributivo e $69,46 \%$ não contributivo, resultando em um total de 72,34\% em 2002), Chile $(62,99 \%$ contributivo e $14,42 \%$ não contributivo, resultando em 77,26\% em 2003), Uruguai (85,97\% em 2004) e Brasil (86,66\% em 2002).

Essa cobertura era inferior a $60 \% \mathrm{em}$ outros 10 países da América Latina Colômbia (18,61\% em 2000), Equador (33,27\%, sendo $16,08 \%$ contributivo e $18,47 \%$ não contributivo, em 2004), Guatemala (11,17\% em 2000), México (18,70\% em 2002), Panamá (41,86\% em 2003), Paraguai (14,91\% em 2004), Peru (26,19\% em 2003), El Salvador (13,88\% em 2003), Venezuela (26,82\% em 2004) e República Dominicana (13,17\% em 2004 para a população de 65 anos ou mais) -, sendo que seis deles estavam em um patamar igual ou inferior a $20 \%$ e outros quatro na faixa de $20 \%$ a $40 \%$. Tais dados consideram tanto os benefícios contributivos quanto os não contributivos, até porque, para muitos países, as pesquisas domiciliares não permitem separar o recebimento desses tipos de benefícios, sendo possível para Bolívia, Equador, Chile 


\section{Quadro 1: Proteção social dos idosos na América Latina}

\begin{tabular}{|c|c|c|}
\hline Pais & $\begin{array}{l}\text { Cobertura da proteção social dos idosos e } \\
\text { evolução }\end{array}$ & Desigualdade de proteção e outras observações \\
\hline Argentina & $\begin{array}{l}68,8 \% \text { em 2006. Queda se comparado } \\
\text { com } 1992(78,1 \%)-65 \text { anos ou mais para } \\
\text { área urbana. }\end{array}$ & $\begin{array}{l}\text { Em } 2006 \text {, era de } 73,9 \% \text { para homens e } 65,4 \% \text { para } \\
\text { mulheres, ambos com tendência de queda. Variava de } \\
39,9 \% \text { para os } 20 \% \text { mais pobres a } 77,8 \% \text { entre os } 20 \% \\
\text { mais ricos. Tendência de queda para todos os quintis, } \\
\text { em especial os } 40 \% \text { mais pobres. }\end{array}$ \\
\hline Bolívia & $\begin{array}{l}72,34 \% \text { em } 2002 \text { quando considerados os } \\
\text { beneficios contributivos (14,71\%) e não } \\
\text { contributivos ( } 69,46 \%) \text {. Alta se comparado } \\
\text { com } 1996 \text { quando havia apenas } 17,63 \% \\
\text { atendidos pelos beneficios não contributivos. }\end{array}$ & $\begin{array}{l}59,96 \% \text { para os } 20 \% \text { mais pobres e } 79,85 \% \text { para os } 20 \% \\
\text { mais ricos, mas considerando apenas os contributivos } \\
\text { seria de } 0,16 \% \text { para os } 20 \% \text { mais pobres em } 1996 \text {. Em } \\
2004 \text { e para os contributivos, seria de } 16,93 \% \text { para homens, } \\
12,87 \% \text { para mulheres; } 5,07 \% \text { rural e } 24,40 \% \text { urbano. }\end{array}$ \\
\hline Chile & $\begin{array}{l}77,26 \% \text { em } 2003 \text {, sendo } 62,99 \% \text { contributivo } \\
\text { e } 14,42 \% \text { não contributivo. Estabilidade se } \\
\text { comparado com } 1990(77,19 \%) \text {, mas com } \\
\text { queda do contributivo (era } 73,04 \% \text { ) e alta } \\
\text { do não contributivo (era } 6,78 \% \text { ) - } 65 \text { anos } \\
\text { ou mais. }\end{array}$ & $\begin{array}{l}\text { Considerando apenas os contributivos seria de } 43,20 \% \\
\text { para os } 20 \% \text { mais pobres e } 68,97 \% \text { para os } 20 \% \text { mais } \\
\text { ricos; } 71,76 \% \text { para os homens e } 56,42 \% \text { para as mulheres; } \\
45,39 \% \text { rural e } 66,52 \% \text { urbano. }\end{array}$ \\
\hline Colômbia & $\begin{array}{l}\text { 18,61\% em 2000. Queda se comparado } \\
\text { com } 1992(20,03 \%) \text { e alta cm relação a } 1995 \\
(13,66 \%)-65 \text { anos ou mais. }\end{array}$ & $\begin{array}{l}24,51 \% \text { para homens e } 13,55 \% \text { para mulheres; } 6,23 \% \text { rural } \\
\text { e } 27,24 \% \text { urbano; } 5,89 \% \text { para os } 20 \% \text { mais pobres e } 44,88 \% \\
\text { para os } 20 \% \text { mais ricos, no ano de } 2000 .\end{array}$ \\
\hline Costa Rica & $\begin{array}{l}60,09 \% \text {, sendo } 39,42 \% \text { contributivo e } \\
20,12 \% \text { não contributivo em } 2004 \text {. Alta em } \\
\text { relação a } 1991(25,56 \% \text {, havendo apenas } \\
\text { contributivos). }\end{array}$ & $\begin{array}{l}\text { Considerando apenas os contributivos, seria de } 10,79 \% \\
\text { para os } 20 \% \text { mais pobres e } 62,05 \% \text { para os } 20 \% \text { mais } \\
\text { ricos; } 51,13 \% \text { homens e } 29,25 \% \text { mulheres; } 24,45 \% \text { rural } \\
\text { e } 47,59 \% \text { urbano. }\end{array}$ \\
\hline El Salvador & $\begin{array}{l}\text { 13,88\% em 2003. Alta comparado a } 1997 \\
(12,35 \%) \text {. }\end{array}$ & $\begin{array}{l}19,81 \% \text { para homens e } 9,38 \% \text { para mulheres; } 3,89 \% \text { rural } \\
\text { e } 20,0 \% \text { urbano; } 1,13 \% \text { para os } 20 \% \text { mais pobres e } 32,61 \% \\
\text { para os } 20 \% \text { mais ricos. }\end{array}$ \\
\hline Equador & $\begin{array}{l}33,27 \% \text { em } 2004 \text { quando considerados os } \\
\text { beneficios contributivos }(16,08 \%) \text { e não } \\
\text { contributivos }(18,47 \%) \text {. Para os contributivos, } \\
\text { queda se comparado com } 1990(18,60 \%) \text { e } \\
\text { alta se comparado com } 2000(13,68 \%) \text {. } \\
\text { Os beneficios não contributivos começaram } \\
\text { a ser pagos em 2000. Portanto, a cobertura } \\
\text { total cresceu significativamente frente a } 1999 \\
\text { (22,38\%, apenas contributivos). }\end{array}$ & $\begin{array}{l}\text { Considerando apenas os contributivos, seria de } 19,38 \% \\
\text { para homens e } 12,95 \% \text { para mulheres; } 5,45 \% \text { rural e } \\
23,17 \% \text { urbano; } 2,03 \% \text { para os } 20 \% \text { mais pobres e } \\
36,97 \% \text { para os } 20 \% \text { mais ricos. }\end{array}$ \\
\hline Guatemala & $\begin{array}{l}\text { 11,17\% em 2000. Queda comparado a } 1998 \\
(13,73 \%) \text {. }\end{array}$ & $\begin{array}{l}19,10 \% \text { para homens e } 3,59 \% \text { para mulheres; } 6,89 \% \\
\text { rural e } 16,46 \% \text { urbano; } 0,67 \% \text { para os } 20 \% \text { mais pobres } \\
\text { e } 26,08 \% \text { para os } 20 \% \text { mais ricos em } 2000 .\end{array}$ \\
\hline México & $\begin{array}{l}18,70 \% \text { em 2002. Alta se comparado com } \\
1992(16,66 \%) \text {. }\end{array}$ & $\begin{array}{l}26,18 \% \text { para homens e } 12,14 \% \text { para mulheres; } 7,97 \% \text { para } \\
\text { rural e } 23,40 \% \text { para urbano; } 2,97 \% \text { para os } 20 \% \text { mais } \\
\text { pobres e } 30,13 \% \text { para os } 20 \% \text { mais ricos. }\end{array}$ \\
\hline Panamá & $\begin{array}{l}41,86 \% \text { em 2003. Alta se comparado com } \\
1991(35,55 \%) \text {. }\end{array}$ & $\begin{array}{l}48,72 \% \text { para homens e } 35,04 \% \text { para mulheres; } 17,69 \% \\
\text { rural e } 57,625 \text { para urbano; } 5,16 \% \text { para os } 20 \% \text { mais } \\
\text { pobres e } 73,96 \% \text { para os } 20 \% \text { mais ricos em } 2003 \text {. }\end{array}$ \\
\hline Paraguai & $\begin{array}{l}14,91 \% \text { cm 2004, Queda se comparado com } \\
1999(17,39 \%) \text {. }\end{array}$ & $\begin{array}{l}15,23 \% \text { para homens e } 14,64 \% \text { para mulheres; } 6,64 \% \text { rural c } \\
21,39 \% \text { urbano; } 1,03 \% \text { para os } 20 \% \text { mais pobres e } 37,85 \% \\
\text { para os } 20 \% \text { mais ricos em } 2004 \text {. }\end{array}$ \\
\hline Peru & $\begin{array}{l}26,19 \% \text { em } 2003 \text {. Queda se comparado } \\
\text { a } 1998(29,85 \%) \text {. }\end{array}$ & $\begin{array}{l}34,49 \% \text { para homens e } 18,62 \% \text { para mulheres; } 5,72 \% \text { para } \\
\text { rural e } 38,80 \% \text { para urbano; } 0,95 \% \text { para os } 20 \% \text { mais } \\
\text { pobres e } 58,46 \% \text { para os } 20 \% \text { mais ricos. }\end{array}$ \\
\hline $\begin{array}{l}\text { República } \\
\text { Dominicana }\end{array}$ & $\begin{array}{l}13,17 \% \text { em } 2004 \text {. Alta se comparado com } \\
2000(10,99 \%)-65 \text { anos ou mais. }\end{array}$ & $\begin{array}{l}18,77 \% \text { para homens e } 7,42 \% \text { para mulheres; } 6,02 \% \\
\text { para rural e } 18,26 \% \text { para urbano; } 4,44 \% \text { para os } 20 \% \\
\text { mais pobres e } 21,64 \% \text { para os } 20 \% \text { mais ricos em } 2004 \text {. }\end{array}$ \\
\hline Uruguai & $\begin{array}{l}85,97 \% \text { em } 2004 \text {. Queda se comparado } \\
\text { a } 1995(87,62 \%) \text {. }\end{array}$ & $\begin{array}{l}87,44 \% \text { para homens e } 85,03 \% \text { para mulheres; } 78,05 \% \\
\text { para os } 20 \% \text { mais pobres e } 87,10 \% \text { para os } 20 \% \text { mais ricos. }\end{array}$ \\
\hline Venezuela & $\begin{array}{l}26,82 \% \text { em } 2004 \text {. Alta se comparado com } \\
1995(18,79 \%) \text {. }\end{array}$ & $\begin{array}{l}33 \% \text { para homens e } 21,73 \% \text { para mulheres; } 11,84 \% \text { para } \\
\text { os } 20 \% \text { mais pobres e } 47,37 \% \text { para os } 20 \% \text { mais ricos. }\end{array}$ \\
\hline
\end{tabular}

Fonte: Elaboração a partir de dados Rofman e Luccheti (2007). 
e Costa Rica, onde o percentual de idosos que recebe benefícios desse tipo é de, respectivamente, $69,46 \%, 18,47 \%, 14,42 \%$ e $20,12 \%$. Portanto, a cobertura seria ainda mais baixa, sem considerar os benefícios não contributivos.

A baixa cobertura dos idosos reflete, entre outros fatores, a precariedade do mercado de trabalho da região, caracterizado por elevada informalidade, bem como a incapacidade do modelo de desenvolvimento dos países da América Latina de construir um sistema de proteção social abrangente e adequado. Ademais, a baixa proteção social dos idosos afeta de forma muito desigual os diferentes grupos da sociedade, sendo mais um reflexo de modelo de desenvolvimento que criou elevada desigualdade. São afetados de forma mais severa os que vivem nas áreas rurais, os mais pobres, e os com menor escolaridade. Em geral, há uma menor proteção para as mulheres vis-à-vis os homens e para determinados grupos raciais/étnicos que historicamente foram alvo de discriminação, como indígenas e negros.

No tocante à tendência da proteção social, Rofman \& Luccheti (2007) apontam que essa seria um mix de melhora em alguns países, com piora em outros, havendo dificuldade de definir uma tendência geral. As mudanças seriam lentas e pequenas, prevalecendo um quadro geral de proteção social muito baixo para os idosos da América Latina. Na maioria dos países, como constata Mesa Lago (2007), não é possível mensurar de forma precisa o impacto de reformas previdenciárias recentes na cobertura dos idosos, seja por terem ocorrido há muito pouco tempo ou por insuficiência de registros estatísticos. De todo modo, em alguns países da região, podese sugerir alguma relação entre a evolução da cobertura e a adoção de novos modelos previdenciários.

No Chile, a cobertura permaneceu relativamente constante entre 1990 e 2003. No entanto, separando-se os benefícios, observa-se que a cobertura dos contributivos baixou, enquanto a dos assistenciais aumentou. Esses resultados sugerem que a reforma estrutural implantada em 1981, substituindo completamente o modelo público por um modelo privado, pode ter

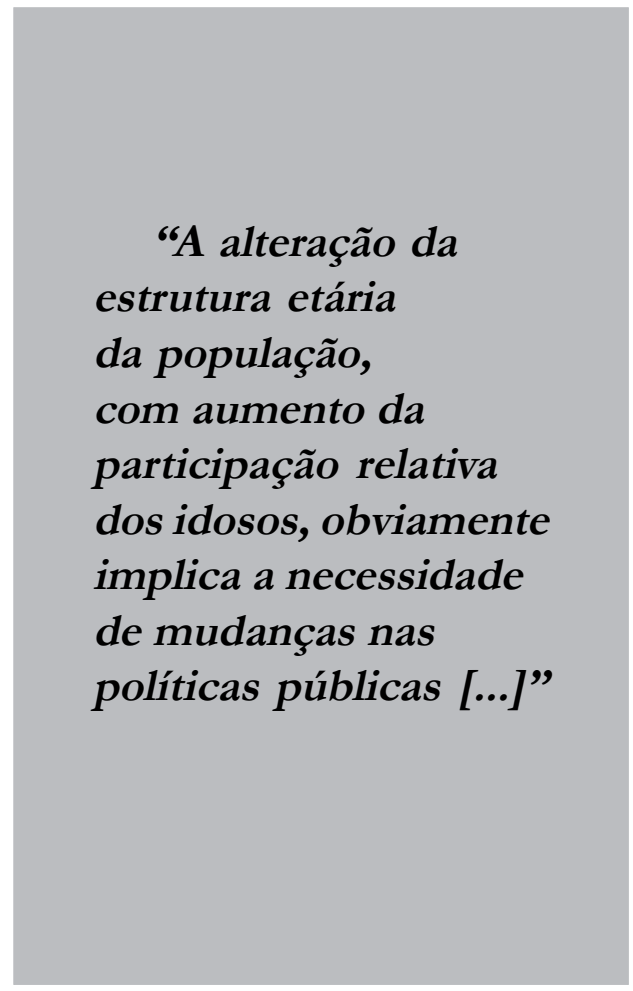

contribuído para dificultar o acesso aos benefícios contributivos. $\mathrm{Na}$ Bolívia, onde reforma similar foi realizada em 1997, a proteção aos idosos aumentou basicamente em função da expansão da cobertura assistencial, mediante a instituição do denominado Bônus Solidário, benefício anual e vitalício de caráter pessoal e destinado a idosos com idade igual ou superior a 65 anos. $\mathrm{Na}$ Colômbia, que em 1994 também optou 
por uma reforma estrutural, migrando para um modelo paralelo de Previdência Social, no qual há competição entre sistema público e privado, os registros restritos aos benefícios contributivos mostram retração da cobertura entre 1992 e 2000.

No caso colombiano, cabe destacar o chamado Fundo de Solidariedade Pensional - uma conta especial do governo federal daquele país -, vinculado ao Ministério da Proteção Social, que tem como finalidade ampliar a cobertura mediante subsídio às contribuições de grupos da população que, por suas características e condições socioeconômicas, não têm acesso aos sistemas de seguridade social; e oferta de benefícios para a proteção social de idosos em situação de indigência ou pobreza nesse último caso, com desenho e função muito similares ao BPC-Loas.

Costa Rica e Argentina instituíram reformas estruturais que deram origem a modelos mistos de Previdência Social, caracterizados pela integração de sistema público, que outorga um benefício básico, e sistema privado, que oferece um benefício complementar. No primeiro país, a cobertura aumentou também em função dos benefícios contributivos, mas principalmente em razão da concessão de benefícios não contributivos. $\mathrm{Na}$ Argentina, a cobertura dos idosos de 65 anos ou mais caiu de 76,7\% em 1994 para 71,8\% em 1999 (Bertranou, 2001), quase um ponto percentual por ano de decréscimo, desde a mudança de modelo. ${ }^{6}$ Entre outros fatores, uma possível explicação para a diferença nos resultados reside no fato de que, no caso argentino, o peso dos benefícios não contributivos sobre o total de benefícios da seguridade social é menor $-10,1 \%$, em dezembro/2000 -, segundo Schwarzer \& Quirino (2002).
Os dados deixam claro que, de modo geral, a proteção social dos idosos na América Latina é bastante precária e heterogênea, variando de países com cobertura de $80 \%$ a países com proteção abaixo de $20 \%$. O mais importante é salientar que, em vários países, a melhora da proteção social esteve relacionada à introdução de benefícios de caráter não ou semicontributivo, como a Previdência Rural, ou mesmo de caráter assistencial ou não contributivo, como o Benefício de Prestação Continuada (BPCLoas), no caso brasileiro, mas que também foi realidade para outros países como Bolívia, Chile, Colômbia e Costa Rica.

Com as informações já apresentadas, é possível fazer, com limitações, uma estimativa da proteção social dos idosos na América Latina. Utilizando os dados de população com 65 anos ou mais do Celade/Cepal em 2005 e a cobertura descrita do Quadro 1, pode-se estimar que, dos cerca de 30,7 milhões de pessoas com 65 anos ou mais na América Latina (inferior ao dado da Tabela 2, pois não considera todos os países, apenas aqueles para os quais há informação sobre cobertura), 16,9 milhões contavam com proteção $(54,9 \%$ ) e 13,8 milhões (45,1\%) eram desprotegidos (Tabela 5).

A médio e longo prazos, o aperfeiçoamento da proteção social dos idosos na América Latina passa necessariamente por uma melhor estruturação dos mercados de trabalho da região, com redução da informalidade e ampliação da proteção social, bem como diminuição dos chamados working poor (trabalhadores ocupados com baixo nível de renda e incapacidade de contribuição). Contudo, a curto prazo, a análise da evolução recente da proteção social dos países da América Latina indica que a ampliação da cobertura depende da criação de mecanismos semi ou não contributivos, que geram 
Tabela 5: Proteção social dos idosos na América Latina

\begin{tabular}{c|c|c|c}
\hline \multirow{2}{*}{ Região } & \multicolumn{3}{|c}{ População com 65 anos ou mais } \\
\cline { 2 - 4 } & Protegidos (a) & Desprotegidos (b) & Total (a + b) \\
\hline $\begin{array}{l}\text { América Latina (inclui apenas } \\
\text { os países com dados de cobertura) }\end{array}$ & 16.855 .391 & 13.845 .935 & 30.701 .326 \\
\hline
\end{tabular}

Fonte: Estimativa elaborada a partir de dados da Celade/Cepal e Rofman e Luccheti (2007).

distribuição de renda e ampliação da seguridade social. A focalização em esquemas de proteção social dos idosos unicamente ou quase exclusivamente contributivos resulta em mera reprodução das desigualdades profundas que existem no mercado de trabalho e da precariedade na proteção, tendo em vista o alto grau de informalidade.

Ademais, a transformação de regimes de repartição pública em esquemas de capitalização de contas individuais tende, ceteris paribus, a reforçar o componente contributivo dos esquemas de proteção social, sem maiores ganhos em termos de ampliação da proteção social dos idosos.

\section{Efeitos ou impactos da proteção social dos idosos brasileiros}

Como o objetivo principal da Previdência Social é garantir renda ao trabalhador em idade avançada, a taxa de participação dos idosos no mercado de trabalho consiste em indicador fundamental para avaliar o impacto da política previdenciária na vida dos beneficiários. Como mostra o Gráfico 4 , os resultados encontrados, de modo geral, são coerentes com a tese de que os benefícios previdenciários ${ }^{7}$ provocam impactos positivos e não desprezíveis na decisão de seus beneficiários quanto à participação ou não no mercado de trabalho.

Entre os idosos do sexo masculino, fica evidente a diferença na taxa de participação de beneficiários e não beneficiários da previdência social, embora para os dois grupos essa tenda a decrescer com a idade. A participação média do total de homens beneficiários com idade igual ou superior a 60 anos é de 34,9\%, menos da metade da participação dos homens não beneficiários situados na mesma faixa etária $(76,7 \%)$. No caso das mulheres, o impacto da previdência não está tão evidente. A diferença de participação dos dois grupos é menor, ficando em $18 \%$ entre as beneficiárias e em 25,1\% entre as não beneficiárias, mas não deve ser subestimada.

De acordo com Schwarzer \& Paiva (2003), a proximidade verificada nas taxas de participação por idade de mulheres beneficiárias e não beneficiárias pode estar relacionada à existência de padrões distintos de inserção no ambiente familiar, não observados entre os homens, para os dois grupos. Pouco mais da metade $(54,1 \%)$ das beneficiárias ocupa posição de pessoa de referência, categoria que tradicionalmente tende a participar mais do mercado de trabalho porque dela costuma depender a maior parte do núcleo familiar. No entanto, apenas 29\% das não beneficiárias são chefes de família. Entre os homens, como pode ser visto na Tabela 6 , as diferenças no perfil de beneficiários e não beneficiários são quase inexistentes.

No caso das mulheres beneficiárias, ocorrem dois movimentos em sentidos contrários, que aparentemente tendem a se 


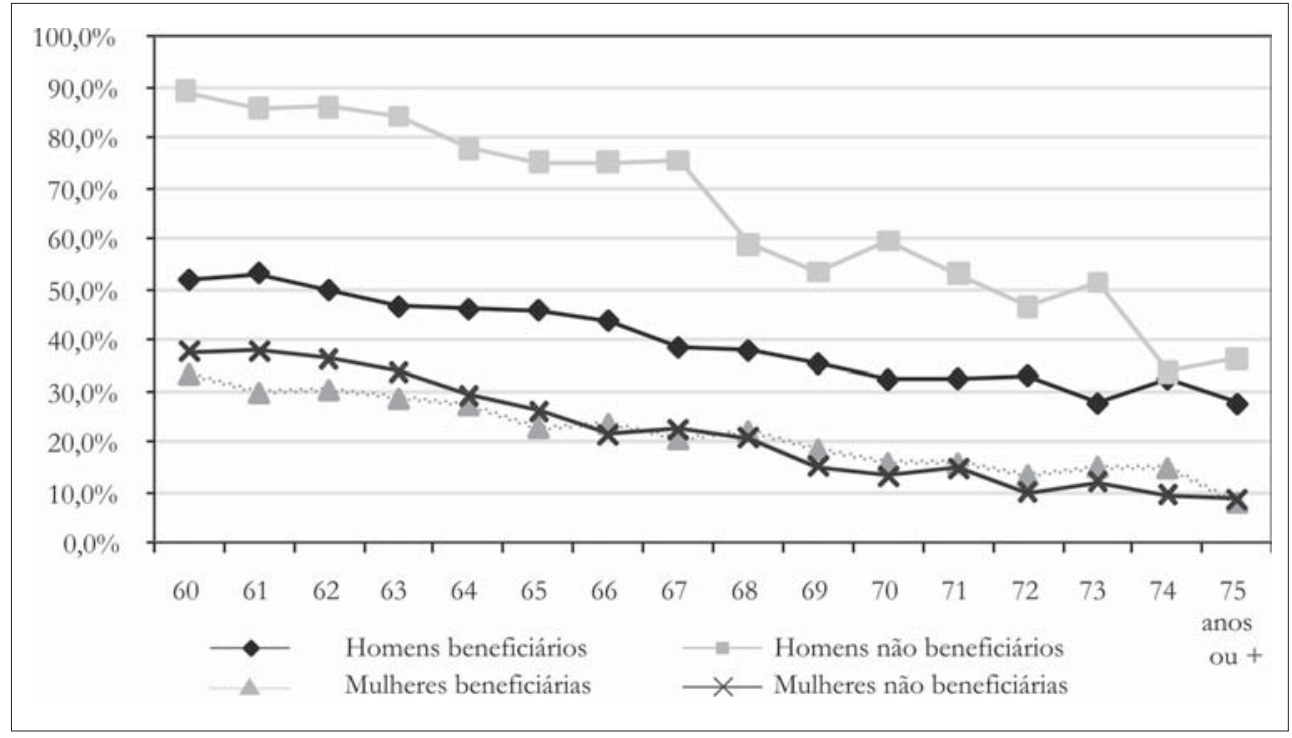

Fonte: PNAD/IBGE - 2007. Elaboração: SPS/MPS.

Gráfico 4: Taxa de participação no mercado de trabalho por sexo e segundo a situação perante a Previdência Social (beneficiários ou não) - 2007

Tabela 6: Distribuição de beneficiários e não beneficiários segundo condição na unidade familiar e sexo - 2007

\begin{tabular}{l|r|r|r|r}
\hline \multicolumn{1}{c|}{ Condição na familia } & \multicolumn{1}{c|}{$\begin{array}{c}\text { Homens } \\
\text { beneficiários }\end{array}$} & $\begin{array}{c}\text { Homens não } \\
\text { beneficiários }\end{array}$ & $\begin{array}{c}\text { Mulheres } \\
\text { beneficiárias }\end{array}$ & $\begin{array}{c}\text { Mulheres não } \\
\text { beneficiárias }\end{array}$ \\
\hline Pessoa de referência & $87,2 \%$ & $82,3 \%$ & $54,1 \%$ & $29,0 \%$ \\
\hline Cônjuge & $6,4 \%$ & $10,2 \%$ & $27,9 \%$ & $59,6 \%$ \\
\hline Filho & $0,2 \%$ & $0,8 \%$ & $0,5 \%$ & $0,9 \%$ \\
\hline Outros parentes & $5,8 \%$ & $5,9 \%$ & $17,0 \%$ & $9,7 \%$ \\
\hline Outras situações & $0,4 \%$ & $0,7 \%$ & $0,6 \%$ & $0,9 \%$ \\
\hline Total & $\mathbf{1 0 0 , 0} \%$ & $\mathbf{1 0 0 , 0} \%$ & $\mathbf{1 0 0 , 0} \%$ & $\mathbf{1 0 0 , 0} \%$ \\
\hline
\end{tabular}

Fonte: PNAD/IBGE - 2007. Elaboração: SPS/MPS. 
anular. O rendimento recebido por meio do benefício previdenciário atua no sentido de favorecer a queda na taxa de participação no mercado de trabalho. $\mathrm{O}$ elevado percentual de mulheres beneficiárias na condição de pessoa de referência, entretanto, pressiona a taxa de participação para cima. Entre as não beneficiárias, apesar da inexistência de rendimentos previdenciários, a pouco expressiva parcela de chefes de família tende a manter a taxa de participação em nível mais baixo. O resultado dessa combinação de forças é a já mencionada semelhança da participação dos dois grupos no mercado de trabalho; situação que tenderia a não ocorrer caso a condição na unidade familiar fosse a mesmo para beneficiárias e não beneficiárias - a taxa de participação das primeiras possivelmente seria significativamente inferior à das segundas.
Ressalte-se que, ao longo do período 1992-2007, os dados relativos à participação confirmam a tendência de menor participação de beneficiários da Previdência no mercado de trabalho, como meio de complementação de renda (Gráfico 5). No período analisado, a taxa de participação caiu ou, ao menos, permaneceu relativamente estável em quase todos os grupos, exceto para as mulheres não beneficiárias. Em todos os casos, o diferencial entre beneficiários e não beneficiários de ambos os sexos manteve-se evidente.

Uma forma de avaliar o impacto da proteção e da posição no domicílio sobre a probabilidade de participar ou não do mercado de trabalho é fazer uma análise por meio de uma regressão logística binária: tomando a participação ou não no mercado de trabalho como a variável

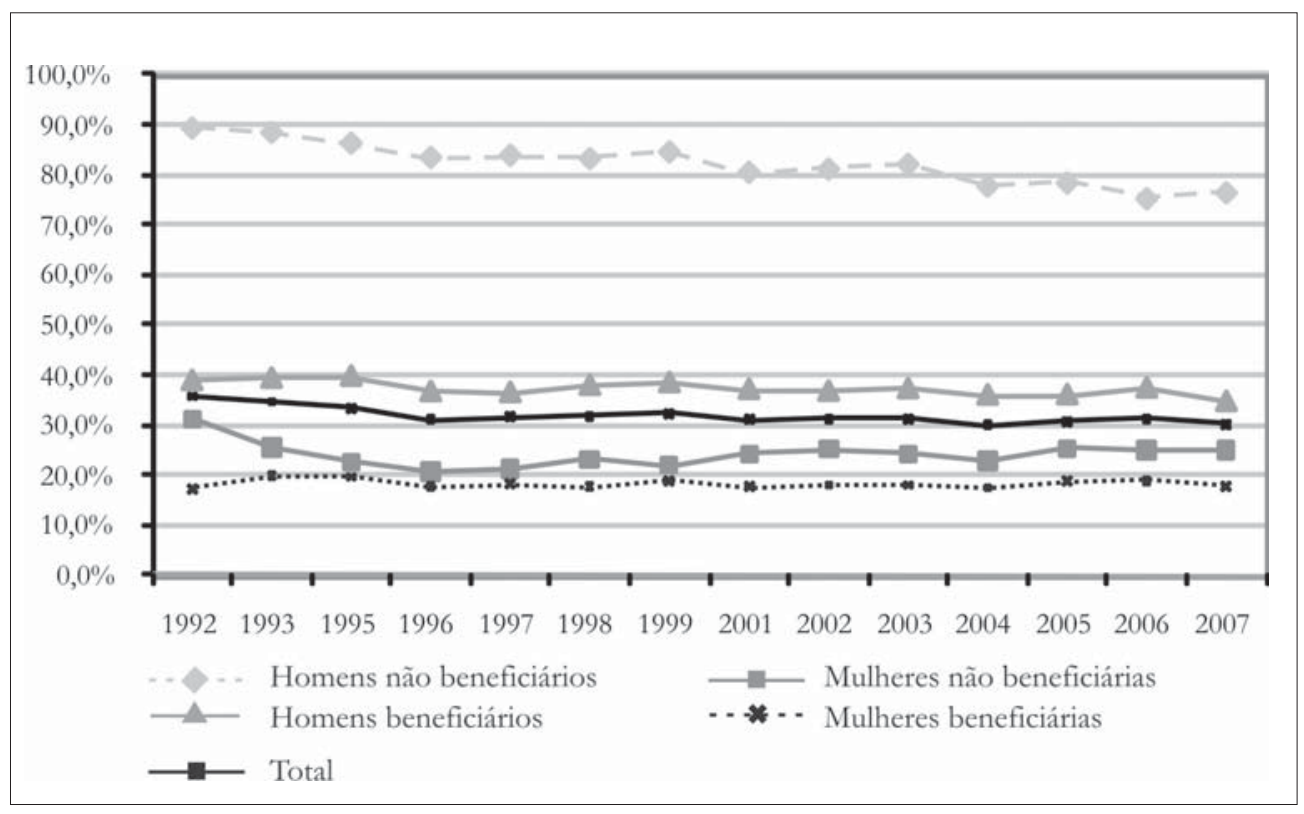

Fonte: PNAD/IBGE - 1992 a 2007. Elaboração: SPS/MPS

Gráfico 5: Taxa de participação no mercado de trabalho de residentes idosos, segundo sexo e situação previdenciária - 1992-2007, 2007 
independente (sendo 1 para inativo e 0 para ativo) e as variáveis dependentes sendo proteção social (1 para protegido e 0 para não protegido), dummy de sexo (sendo 0 para mulher e 1 para homem) e dummy de posição no domicílio (sendo 1 para pessoa de referência e 0 para as demais). Como mostrado pela Tabela 7, o fato de um idoso ter proteção social aumenta a probabilidade de que esse se encontre fora da População Economicamente Ativa (PEA), ou seja, esteja inativo, denotando o impacto positivo da proteção social.

Esse efeito foi mensurado isolando-se o impacto da posição no domicílio que, como discutido anteriormente, tornava mais obscuro o impacto positivo da proteção social sobre a não participação na PEA, no caso das mulheres. Os dados da Tabela 7 mostram que ser pessoa de referência, isolados os efeitos de sexo e proteção social, implica uma redução da probabilidade de estar fora da PEA ou, de forma inversa, aumenta a probabilidade de estar ativo, mesmo sendo idoso. A dummy sexo indicou que, isolados os efeitos de pessoa de referência e proteção, ser homem reduzia a probabilidade de estar fora da PEA em relação a ser mulher provavelmente em decorrência do fato de que entre os idosos atuais havia uma diferença de participação na PEA muito grande entre homens e mulheres, ainda maior do que a atual prevalência.

Importante aspecto adicional do impacto da Previdência Social diz respeito à relevância das transferências previdenciárias para a redução da pobreza. A estimativa desse impacto foi elaborada tomando-se em conta a quantidade de pessoas com renda domiciliar per capita abaixo de meio salário mínimo - valor definido para a "linha de pobreza", conforme se inclui ou exclui a renda previdenciária. Seguindo esse critério, em 2007, havia 56,87 milhões de pessoas em situação de pobreza, considerando rendas de todas as fontes, número que chega a 79,10 milhões quando excluídos todos os rendimentos oriundos da Previdência Social.

Isso significa que as transferências previdenciárias foram responsáveis pela retirada de 22,23 milhões de pessoas, de todas as faixas etárias, da condição de pobreza $^{8}$. Esse impacto dos benefícios da Previdência Social sobre a pobreza se concentra, naturalmente, na população idosa, tendo em vista que a função básica de benefícios desse tipo é substituir a renda do trabalhador contribuinte quando esse perde a capacidade de trabalho. Embora a redução da pobreza decorrente da expansão da Previdência Social atinja todas as faixas etárias, a renda previdenciária

Tabela 7: Regressão logística binária - probabilidade de participação de idosos na PEA - Brasil - 2007

\begin{tabular}{l|c|c|c}
\hline Variável dependente & B & Significância & Exp (B) \\
\hline Proteção Social & 0,425 & 0 & 1,53 \\
\hline Dummy de sexo & $-1,105$ & 0 & 0,331 \\
\hline Dummy pessoa de referência & $-0,262$ & 0 & 0,769 \\
\hline Constante & 1,186 & 0 & 3,274 \\
\hline
\end{tabular}

Fonte: PNAD/IBGE, 2007. 
privilegia, sobretudo, os com idade superior a 55 anos.

Como destaca Passos et al (2005), a partir dos 55 anos de idade nota-se forte redução no percentual dos que seriam pobres, caso não fossem beneficiários da Previdência Social. Percebe-se que a Previdência é determinante para que a pobreza diminua com o aumento da idade, chegando ao limite inferior de 10\% para a população com 70 anos ou mais (Gráfico 6). Caso não existissem transferências previdenciárias, haveria um ponto (que, para o ano de 2007, é de aproximadamente 50 anos) a partir do qual a pobreza aumentaria significativamente, chegando a cerca de $70 \%$ para a população com idade acima de 70 anos.

Pode-se dizer que os regimes previdenciários têm como objetivo primordial garantir que as fontes de renda do trabalhador e de sua familia sejam mantidas, caso venha a perder, de forma temporária ou permanente, sua capacidade de trabalho. Em outras palavras, a Previdência atua na prevenção da pobreza, particularmente entre os idosos. Nesse sentido, a Previdência Social brasileira parece cumprir com seu papel: não apenas a taxa de participação de seus beneficiários é frequentemente inferior à observada para os demais subgrupos populacionais, mas também o nível de pobreza é reduzido em todas as faixas etárias em função das transferências previdenciárias.

\section{Considerações Finais}

A combinação de elevação da expectativa de vida e redução da taxa de fecundidade tem levado a um processo de envelhecimento populacional não apenas no Brasil como em toda a América Latina, o que implica maior participação dos idosos na população total e o agravamento da razão de dependência.

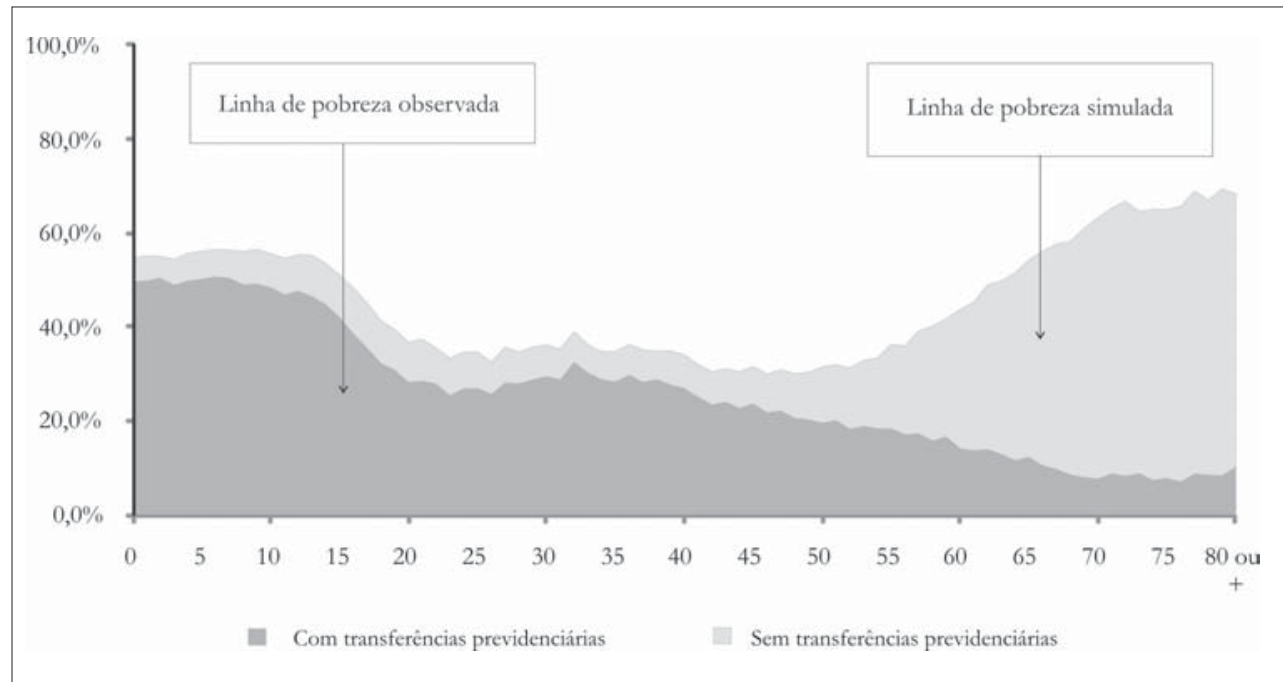

Fonte: PNAD/IBGE - 2007. Elaboração: SPS/MPS.

Gráfico 6: Percentual de pessoas com menos de 1/2 salário mínimo de renda domiciliar per capita no Brasil por idade, considerando a renda previdenciária, 2007 
No Brasil, de 1992 a 2007 notou-se uma melhora da proteção social de idosos, em especial entre as mulheres de 60 anos ou mais. Esse aumento da cobertura decorreu, entre outros fatores, do aumento do número de beneficiários da Loas e das mudanças na Previdência Rural, como a instituição da categoria de segurado especial. Portanto, a melhora da proteção social dos idosos no Brasil está relacionada ao fortalecimento de programas de caráter não ou semicontributivo. Em outros países da América Latina, a ampliação da proteção social dos idosos esteve associada à instituição ou ao fortalecimento de programas de proteção de caráter semi ou não contributivo.

Deveria ser óbvio que programas tradicionais da Previdência Social, baseados exclusivamente no princípio contributivo, não são capazes de universalizar a cobertura da Previdência Social na América Latina, apesar de sua importância e mérito. Esses programas enfrentam dificuldades para incluir os setores da economia familiar rural e urbana e o chamado setor informal. A elevada pobreza, seja estrutural ou resultante da instabilidade econômica e social das últimas décadas, é outro obstáculo ao incremento da proteção social por meio de programas contributivos na América Latina.

Além de cobrar a contribuição dos que são capazes de fazê-la, uma política que tenha por objetivo aumentar a cobertura da proteção social demandará novas formas de financiamento que não sejam baseadas em contribuições monetárias individuais, para incorporar os grupos que não são capazes de manter contribuições regulares. Obviamente, programas exclusivamente contributivos não servem para distribuir renda e apenas tendem a reproduzir as desigualdades existentes no mercado de trabalho que, no caso da América Latina, significa um setor com alta informalidade, elevada precariedade e má distribuição de renda.

(Artigo recebido em abril de 2009. Versão final em julho de 2009).

\section{Notas}

1 Exclusive 1994 e 2000, anos em que a PNAD não foi a campo. Não inclui os dados da área rural da Região Norte, exceto do Estado do Tocantins, nos anos de 2004 a 2007, para garantir a mesma cobertura geográfica do período de 1992 a 2003. Há discrepância entre os dados da PNAD e os da Projeção da População.

${ }^{2}$ O Estatuto do Idoso (Lei no 10.741/2003), vigente desde janeiro de 2004, reduziu - de 67 para 65 anos - a idade mínima para acesso ao benefício assistencial, além de ter flexibilizado o cálculo do limite máximo de $1 \frac{1}{4}$ de salário mínimo de renda familiar per capita, também necessário para a concessão do benefício. De todo modo, os resultados recentes merecem uma análise mais aprofundada, especialmente no que toca aos efeitos da expansão da população idosa.

${ }^{3}$ O segurado especial, segundo os incisos VII dos arts. 12 e 11 das Leis nos 8.212 e 8.213, ambas de 1991, respectivamente, é a pessoa física residente no imóvel rural ou em aglomerado urbano ou rural próximo a ele que, individualmente ou em regime de economia familiar, ainda que com o auxílio eventual de terceiros, a título de mútua colaboração, na condição de: produtor, 
seja proprietário, usufrutuário, possuidor, assentado, parceiro ou meeiro outorgados, como datário ou arrendatário rurais, que explore atividade agropecuária (em área de até quatro módulos fiscais) ou de seringueiro ou extrativista vegetal (desde que exerça suas atividades nos termos do inciso XII do caput do art. $2^{\circ}$ da Lei no 9.985 , de 18 de julho de 2000, e faça dessas atividades o principal meio de vida); de pescador artesanal ou a este assemelhado, que faça da pesca profissão habitual ou principal meio de vida; e de cônjuge ou companheiro, bem como filho maior de 16 anos de idade ou a este equiparado, que comprovadamente trabalhem com o grupo familiar respectivo. A contribuição do segurado especial é de 2,1\% sobre a receita bruta decorrente da comercialização da produção rural.

${ }^{4}$ Dado o caráter amostral da pesquisa, oscilações dessa natureza, observadas em períodos imediatamente anteriores, devem ser tomadas com precaução. É precoce reconhecer nos dados uma reversão da tendência, até então consistente, de elevação da cobertura.

${ }^{5}$ Nesses anos foram realizados suplementos específicos sobre os programas de transferência de renda.

${ }^{6}$ Os dados de Bertranou (2001) e Rofman \& Luccheti (2007) não contemplam os efeitos das novas reformas aprovadas em 2007, com o intuito de fortalecer o pilar público do modelo previdenciário argentino.

${ }^{7}$ Como a PNAD não permite que os benefícios assistenciais sejam dissociados dos benefícios previdenciários, ao longo deste estudo tratamos do impacto dos benefícios pagos pela seguridade social - exceto na área da saúde.

${ }^{8}$ Supondo que tudo mais permaneça constante, ou seja, considerando que todas as demais variáveis que interferem no nível de pobreza não sofram alterações e descartando possíveis impactos das transferências previdenciárias nas decisões dos indivíduos beneficiados direta ou indiretamente.

\section{Referências}

Batista, Analía Soria; Jaccoud, Luciana de Barros; Aquino, Luseni e Dario El-Morr, Patrícia. 2008. Envelhecimento e dependência: desafios para a organização da proteção social. Coleção da Previdência Social. v. 28. Brasília, nov. de 2008.

Bertranou, Fabio; Grushika, Carlos e Rofman, Rafael. Evolución reciente de la cobertura previsional en Argentina. In: BERTRANOv. p. 29-55.

Bolívia. Superintendencia de Pensiones, Valores y Seguros - SPVS. Disponível em: $<$ http://www.spvs.gov.bo>. Acessos em diversas datas.

Brasil. Lei no 10.741 de $1^{\circ}$ de outubro de 2003 (Estatuto do Idoso).

. Ministério da Previdência Social. Informe da Previdência Social. 2008.

Evolução recente da proteção social e seus impactos sobre a pobreza. v. 20, n. 10, out. 2008.

Instituto Brasileiro de Geografia e Estatística - IBGE. Pesquisa Nacional de Amostra de Domicílios - PNAD. Microdados. 1992 a 2007.

2008a.

Projeção da população do Brasil por sexo e idade 1980-2050 - Revisão 
. Síntese de Indicadores Sociais - Uma análise das condições de vida da população brasileira, 2008b.

Centro latino-Americano e Caribenho de Demografia - Celade/Cepal. Disponível em: <http://www.eclac.cl/celade>. Acessos em diversas datas.

Colômbia. Ministerio de la Protección Social. Sistema General de Pensiones. Bogotá, 2008. diversas datas. . Disponível em: <http://www.minproteccionsocial.gov.co>. Acessos em datas. . Disponível em: <http://www.prosperarhoy.com>. Acessos em diversas Costanzi, Rogerio; Ansiliero, Graziela. 2008. Evolução, determinantes e efeitos da proteção social entre os idosos no Brasil. Informe da Previdência Social, v. 20, n. 9, set. 2008. Disponível em: <http://www.mps.gov.br>.

Mesa-Lago, Carmelo. As reformas de previdência na América Latina e seus impactos nos princípios de seguridade social. Brasília: Ministério da Previdência Social, 2007. 190 p. Coleção Previdência Social. Disponível em: <http://www.mps.gov.br>.

Passos, Alessandro Ferreira et al. Previdência Social e Pobreza. Informe de Previdência Social, v. 17, n. 9. Brasília: MPS, set. 2005.

Rofman, Rafael; Luccheti, Leonardo. Pension Systems in Latin America: concepts and measurements of coverage. Discussion Paper n ${ }^{\circ}$ 616. Social Protection World Bank. November 2006. Versão atualizada em janeiro de 2007.

Schwarzer, Helmut; Paiva, Luis Henrique e SAntana, Rafael. Cobertura Previdenciária: evolução 1999-2002 e aperfeiçoamento metodológico. Informe da Previdência Social, v. 16, n. 5, maio de 2004. Disponível em: <http://www.mps.gov.br>.

Schwarzer, Helmut; Paiva, Luis Henrique. Participação de Beneficiários e Não Beneficiários da Previdência Social no Mercado de Trabalho. Informe de Previdência Social, v. 15, n. 11, nov. 2003. Disponível em: <http://www.mps.gov.br>.

Schwarzer, Helmut e Querino, Ana Carolina. Benefícios sociais e pobreza: programas não contributivos da seguridade social brasileira. Textos para Discussão n. 929. Brasília: Ipea, 2002. 


\section{Resumo-Resumen-Abstract}

\section{Evolução recente e alguns determinantes da proteção social dos idosos na América Latina e no Brasil \\ Rogério Nagamine Costanæi e Graziela Ansiliero}

A existência de um sistema de proteção social aos idosos, com ampla cobertura, é extremamente importante para prevenir o aumento da pobreza e da desigualdade. Na ausência de tal sistema, e frente a transformações demográficas e da estrutura familiar presentes em grande parte dos países da América Latina, haverá riscos crescentes de que tanto o Brasil, como outros países da região, sofram com problemas de insuficiência de renda entre as pessoas com idade mais avançada. Dado esse contexto, este artigo avalia a situação atual e as perspectivas de proteção dos idosos na América Latina, com foco no caso brasileiro. Para o Brasil, as referências foram a Pesquisa Nacional por Amostra de Domicílios (PNAD/IBGE) e projeções realizadas pelo Instituto Brasileiro de Geografia e Estatística (IBGE), enquanto os dados relativos à América Latina foram obtidos no Centro Latino Americano e Caribenho de Demografia (Celade/Cepal) e em revisão de literatura sobre o tema. As análises indicaram que o aumento do nível de proteção social na região parece depender de formas de financiamento não baseadas exclusivamente em contribuições monetárias individuais, de modo que seja possível incorporar aqueles grupos incapazes de manter contribuições regulares para os regimes de Previdência.

Palavras-chave: seguridade social, previdência social, transição demográfica.

Evolución reciente y algunos determinantes de la protección social de los mayores en América Latina y Brasil

Rogério Nagamine Costanzi y Graziela Ansiliero

La existencia de un sistema de protección social para los adultos mayores, con amplia cobertura, es sumamente importante para prevenir el aumento de la pobreza y de la desigualdad. En la ausencia de un sistema de este tipo, y en razón de los cambios demográficos y de la estructura familiar presentes en la mayoría de los países de América Latina, habrá riesgos crecientes de que tanto Brasil como los otros países de la región, sufran con problemas de insuficiencia de ingresos entre las personas de edad avanzada. En este contexto, este artículo evalúa la situación actual y las perspectivas de protección de los ancianos en América Latina, particularmente para el caso brasileño. Para el Brasil, las referencias fueran la Pesquisa Nacional por Muestra de Hogares (PNAD/IBGE) y proyecciones realizadas por el Instituto Brasileño de Geografía y Estadística (IBGE), mientras los dados relativos a la América Latina fueran obtenidos en el Centro Latino Americano y Caribeño de Demografía (Celade/Cepal) y en revisión de la literatura pertinente. Los análisis revelaron que el nivel de protección social en la región parece depender de formas de financiación que no sean basadas únicamente en contribuciones monetarias individuales, de modo que se pueda incorporar a los grupos incapaces de mantener contribuciones regulares a los regímenes de previsión social.

Palabras clave: seguridad social, previsión social, transición demográfica.

\section{Recent evolution of determinants on social protection for the elderly in Latin America and Brazil \\ Rogério Nagamine Costanzi and Graziela Ansiliero}

The existence of a social protection system for the elderly, with broad coverage, is extremely important to prevent the increase of poverty and inequality. In the absence of such a system, and considering the changes on demography and family structure faced by most Latin American countries, 
there will be an increasing risk that Brazil, as well as other countries in the region, might suffer from income insufficiency among old age individuals. Given this context, this article addresses the current situation and the prospects regarding the protection of the elderly in Latin America, particularly in the Brazilian case. For Brazil, the references were the National Household Sample Survey (PNAD/ IBGE) and projections made by the Brazilian Institute of Geography and Statistics (IBGE), while data for other Latin American countries were obtained from the Latin American and Caribbean Demographic Centre (Celade/Eclac) and from a literature review on the subject. The analysis indicated that the level of social protection in the region seems to depend on funding strategies not based solely on individual monetary contributions, so that it may be possible to incorporate those groups unable to maintain regular contributions to social insurance schemes.

Keywords: social security, social insurance, demographic transition.

\section{Rogério Nagamine Costanzi}

Especialista em Políticas Públicas e Gestão Governamental desde 1999, atualmente em exercício no Ministério da Previdência Social. Bacharel e mestre em economia pela Universidade de São Paulo (USP). Contato: rogerio.costanzi@previdencia.gov.br

Graziela Ansiliero

Especialista em Políticas Públicas e Gestão Governamental desde 2000, atualmente em exercício no Ministério da Previdência Social. Bacharel em economia pela Universidade de Brasília (UnB). Contato: graziela.ansiliero@previdencia.gov.br 